\title{
Jiri Dvorak, Wolfgang Gilliar: Musculoskeletal manual medicine, diagnosis and therapy
}

\author{
Thieme Verlag, New York, Stuttgart, 2008, HardCover, 800 pp, 1000 figs., \\ Euro (D) 129,95 CHF 216,00, ISBN: 978-3-13-138281-8
}

\author{
Jean-Yves Jenny
}

Received: 20 December 2010/ Accepted: 21 December 2010/Published online: 6 January 2011

(C) Springer-Verlag 2011

This book presents the theoretical and practical aspects of manual medicine. It begins with a very short overview of the biomechanics of spine and limb joints and neurophysiology of joints and muscles. The next sections about principles of clinical examination, report of results, and imaging are somewhat disappointing and not clearly dedicated to surgeons. The clinical examination of the spine is extensively discussed; the clinical findings are clearly described and analyzed. Even the ribs mobility is individually assessed! However, the spine surgeons are not generally informed about such subtle findings, and the therapeutical help is unclear. The clinical examination of the limb joints is also very extensively described, and this section will be helpful to medicine students, when already experienced surgeons will find no relevant additional information.

Finally, this book may be interesting for students or manual medicine physicians, but senior surgeons and even residents or fellow will probably be disappointed.

Conflict of interest No funds were received in support of this study. 